\title{
BEHAVIOUR OF STEEL COLUMNS UNDER 3-D SEISMIC LOAD
}

\author{
Shigeru SHIMIZU ${ }^{1)}$ \\ ${ }^{1)}$ Department of Civil Engineering, Shinshu University, \\ Wakasato 4-Chome, Nagano 380-8553, Japan
}

\begin{abstract}
In the current Japanese bridge design code, the seismic load of only one direction (1dimension, 1-D) is considered. However, in fact, an actual seismic load has three components for N-S (North-South), E-W (East-West) and U-D (Up-Down) directions. The current paper present a series of numerical results of steel box columns, which are used as piers of viaduct, under 3-D seismic load with 3 components. Two types of ground motion patterns of the main shock and the maximum after shock measured in the Chuetsu Earthquake in 2004 are used as the seismic load. The results indicate that the severer deformation arises in the columns under 2-D (N-S and E-W components) or 3-D seismic load than the 1-D load by the main shock. However, under the after shock, which contains ground motion of higher frequency, 1-D load gives larger displacement.
\end{abstract}

\section{Key Words}

Seismic behaviour, steel box column, vertical component

\section{INTRODUCTION}

This paper describes the results of a dynamic analysis on steel box columns used as a motorway viaduct under the seismic loading.

The ground motion caused by an earthquake has three components for N-S (NorthSouth), E-W (East-West) and U-D (Up-Down) directions. Therefore, when an earthquake arises, a structure built on a seismic area is simultaneously subjected to 3-dimensioned seismic load with the N-S, E-W and U-D components. However, in the current Japanese bridge design code, these three components are considered independently, and therefore a structure is assumed to be subjected the seismic load of only one direction at one time.

The author has been made a series of numerical studies on the behavior of partially concrete filled steel box columns under the seismic load ${ }^{1)-6}$. In author's previous studies ${ }^{4)-6 \text {, }}$ conforming to the Japanese current design code, the ground motion for only one direction is considered. However, to clarify the actual behaviour of a structure caused by an earthquake, three component of the ground motion should been considered. Thus, in the current paper, a numerical analysis is made on the dynamic behaviour of concrete filled steel box columns under the seismic load having three components.

\section{NUMERICAL MODELS}

\subsection{Geometry and materials of the models}

A typical numerical model analyzed in this paper is a square sectioned steel box column filled with concrete at its bottom part, which is often used as a pier of the motorway viaduct. Figure 1 shows a typical numerical model. Within this figure, the global view of the 
model is in the Figure 1 (a), and in (b) and (c) the section shapes are illustrated. This model is same to that used in author's previous studies. The model has its depth of $10 \mathrm{~m}$ and the $3 \mathrm{~m} \mathrm{x}$ $3 \mathrm{~m}$ square section, and is composed of the steel plates with the thickness of $20 \mathrm{~mm}$. The concrete is filled for $3 \mathrm{~m}$ from its bottom. In some cases, stiffeners with $200 \times 20 \mathrm{~mm}$ section are considered inside the box as shown in the Figure 1 (c). The plates consisting the column without the stiffener have the dimension of $2960 \times 20 \mathrm{~mm}$.

\section{Figure 1 Typical Numerical Model}

For the elasto-plastic analysis, materials are assumed to have the tri-linear stress-strain properties. Material properties used in the current study are as follows;

For the steel plates, grade SM490 steel is assumed, which has the nominal yield stress of $315 \mathrm{MPa}$. The initial Young's modulus $E$ of steel is $E=200 \mathrm{GPa}$. After yielding, considering strain-hardening, the tangential of the stress-strain relation is assumed to be $E / 100=20 \mathrm{GPa}$, and beyond the stress of $490 \mathrm{MPa}$, the tangential is $E / 200=10 \mathrm{GPa}$.

For the concrete, initial Young's modulus is $E=30 \mathrm{GPa}$, and Young's modulus after yielding is $E / 10=3 \mathrm{Gpa}$. Beyond the stress of $240 \mathrm{MPa}$ which is the design concrete strength, the tangential is $E / 20=1.5 \mathrm{GPa}$.

With these width and thickness of plates and the material properties, undimensioned width-thickness ratio $R$ of plates composing the column and the undimensioned slenderness ratio $\lambda$ of the column can be calculated, here, $R$ and $\lambda$ are defined as

$$
\begin{aligned}
& R=\frac{b}{t} \sqrt{\frac{12\left(1-v^{2}\right) \sigma_{y}}{k \pi^{2} E}} \\
& \lambda=\frac{1}{\pi} \sqrt{\frac{\sigma_{y}}{E}} \cdot \frac{2 l}{r}
\end{aligned}
$$

where $b$ denotes the plate width, $t$ the plate thickness, $E, v, \sigma_{y}$ are Young's modulus, Poisson's ratio and yield stress of the material, $k$ denotes the buckling coefficient of the plate, $l$ the column length (depth) and $r$ denotes the radius of gyration of area of the column. Substituting above plate dimensions, the material properties mentioned later and the buckling coefficient $k=4.0$ into these formulae, $R$ and $\lambda$ are calculated as $R=3.09$ and $\lambda=0.208$ for the model without the stiffener, and $R=1.02$ and $\lambda=0.204$ for the model with the stiffeners. With these values of $R$ and $\lambda$, the column shall failure with local buckling of the plates consisting the column, and not with the global column buckling.

At the top of the column, a mass of 700 tons is considered which refers the superstructure of the viaduct.

The model is descretized with the 20-nodes solid elements for both the steel and the concrete. The FEM mesh pattern used in this analysis is illustrated in Figure 2. In this figure, the thick line indicates that the concrete is filled up to this level. The analysis is made for the 4 cases; (1) the model with stiffeners and filled with concrete, (2) the model with stiffeners and not filled with concrete, (3) the model without stiffener and filled with concrete, (4) the model without stiffener and not filled with concrete.

\section{Figure 2 FEM Mesh Pattern}

Poisson's ratio $v$ and density $\mu$ of steel are $\nu=0.3$ and $\mu=7.85 \times 10^{-6} \mathrm{~kg} / \mathrm{mm}^{3}$, and those of concrete are $v=0.167$ and $\mu=2.35 \times 10^{-6} \mathrm{~kg} / \mathrm{mm}^{3}$. The elasto-plastic large deflection analysis is 
realized with the combined hardening rule considering the Bauschinger effect.

\subsection{Natural Periods and Damping Factors}

In Table 1, natural period and natural frequency of the numerical models are summarized. The table 1 is obtained from the FEM analysis as an eigenvalue problem.

With the 1-st mode, the model columns show the overall-bending mode, and with the 2-nd mode, plates consisting the columns deform for their out-of-plane directions without column overall bending, as illustrated in Figure 3. With the 1-st mode, the column shall sway with the frequency of from 2.4 to $3.2 \mathrm{~Hz}$, and the stiffeners or the filled-in concrete seems to have small effect. On the other hand, in the 2-nd mode, the models without stiffener have the frequency of 6.1-6.9 Hz and with stiffeners 9.9-11.2 Hz.

\section{Table 1 Natural Period and Natural Frequency of model Columns}

\section{Fig.3 Examples of Natural mode of columns with stiffeners and filled with concrete}

is defined as

In the analysis of this paper, Rayleigh's viscous damping matrix $[\mathrm{C}]$ is used, which $[C]=\alpha[M]+\beta[K]$

where $[C],[M]$ and $[K]$ denote the damping matrix, the mass matrix and the stiffness matrix of the column respectively, and $\alpha$ and $\beta$ are coefficients calculated with the following formula.

$$
\left\{\begin{array}{l}
\alpha \\
\beta
\end{array}\right\}=2 \frac{\omega_{i} \omega_{j}}{\omega_{j}^{2}-\omega_{i}^{2}}\left[\begin{array}{cc}
\omega_{i} & \omega_{j} \\
-1 / \omega_{j} & 1 / \omega_{i}
\end{array}\right]\left\{\begin{array}{l}
h_{i} \\
h_{j}
\end{array}\right\}
$$

In this formula, $\omega_{I}$ and $\omega_{j}$ are the natural frequencies of the structure of the first and the second mode respectively, and $h_{I}$ and $h_{j}$ are the damping factors. In this study, $h_{I}$ and $h_{j}$ are assumed as $h_{I}=h_{j}=0.02$. The calculated values of the coefficients $\alpha$ and $\beta$ are summarized in the Table 2.

In the analysis, three components of the seismic load are assumed to be applying at the top the column. In addition, the mass arranged at the top of the column is considered to be subjected to gravity acceleration, therefore the column is also subjected to the vertical load due to weight of the superstructure.

\section{SEISMIC LOAD}

The seismic load used for the analysis is the ground motion measured at Kawaguchi Town Office in Niigata Prefecture, Japan, of the main shock and the maximum after shock of Chuetsu Earthquake, occurred in Oct. 2004. The main shock of this earthquake occurred at 17:56 of 23, Oct. 2004 (Japanese Standard Time) with the Magnitude of $M=6.8$, and the maximum after shock occurred at 18:34 of the same day with $M=6.5$. The seismic intensity of the main shock measured at Kawaguchi Town near the epicenter of the earthquake was "7", the highest value of the JMA (Japanese Meteorological Agency) scale, and the intensity of the after shock is " $6+$ ". This earthquake is considered to be caused by a typical reverse fault, and 68 fatalities are reported. 
Figure 4 Seismic Load of Main Shock

Figure 5 Seismic Load of Maximum After Shock

The measured ground acceleration and the Fourier spectra for North-South (NS), EastWest (EW) and Up-Down (UD) directions are plotted in Figure 4 for the main shock and in Figure 5 for the after shock. It is found from these figures that, in either shock, very severe ground acceleration is measured in the EW component. In the either shocks, the preliminary tremor continued until about 3,8 seconds followed by the major tremor. This fact can be found very clearly in the NS and EW components of the after shock. In the main shock, the maximum acceleration is 1675 gals at $3,86 \mathrm{sec}$, and in the after shock, the maximum acceleration is 2036 gals at $4.79 \mathrm{sec}$. This fact means that the ground acceleration caused by this earthquake is almost twice of the gravity acceleration.

In the Fourier spectrum of the main shock, extremely severe value of over $800 \mathrm{~cm} / \mathrm{sec}$ is found on $0,8 \mathrm{~Hz}$ in the EW component. This dominant pulse around $1.0 \mathrm{~Hz}$ is often called as the "killer pulse", which brings the destructive damage of structures. However, in the after shock, such spectrum is not found, in spite of the larger acceleration than one of the main shock. In the after shock, the maximum value of the spectrum is found around 4-5 Hz, and the value is about $300 \mathrm{~cm} / \mathrm{sec}$ in $\mathrm{EW}$ component and $500 \mathrm{~cm} / \mathrm{sec}$ in the NS component.

\section{COLUMN BEHAVIOUR UNDER 3-D SEISMIC LOAD}

\subsection{General}

In the current Japanese seismic design code on the steel box columns, the strength is estimated mainly with the displacement at the top of the column. In particular, on the residual horizontal displacement at the top of the column, it is specified to be less than $1 \%$ of the column depth. Therefore, in this paper, the displacement behaviour is discussed.

To simplify the descriptions of this paper, hereafter, the numerical models are denominated as indicated in the Table 2, that is, the models without filled-in-concrete are named as "NCNS" or "NCWS" according with existence of stiffeners, and the models with filled-in-concrete are as "WCNS" or "WCWS". In addition, the seismic load of only E-W component, with N-S and E-W components and all three components shall be expressed as the "1-directioned", the "2-directioned" and the "3-directioned" respectively.

\subsection{Displacement patterns}

Figures 6-8 show the displacement patterns of the columns under the seismic load. Within these figures, in figure 6, patterns of the model with no stiffener and filled with concrete (model NSWC) under the main shock, in figure 7, the model with stiffeners and filled with concrete (model WSWC) under the main shock, and the figure $\mathbf{8}$ is the case with the model NSWC under the after shock are illustrated. In each figure, (a) shows the displacement of the column under the seismic load for only one direction (E-W component), and (b) under the 3-directioned seismic load (N-S, E-W and U-D). The concrete is filled up to the level indicated with the thick black line in each figure.

In figure 6, within the either case of 1-directioned and 3-directioned load, the column has small displacement in the earlier stage (until about 4 seconds from beginning, i.e. during the preliminary tremor). In this stage, no significant out-of-plane displacement is found. 
Beyond 4 seconds, out-of-plane deformation caused by the local buckling begins to develop in the plates constructing the column just above the filled-in concrete. Under 3-directioned load, the horizontal displacement increases rapidly, and at the final stage, the column breaks down with snapping just above the filled-in concrete as illustrated in figure 6 (b).

In the model in figure 7 in which stiffeners are installed, unlike the model in figure 6, the out-of-plane deflection develops under the 3-directioned seismic load in the earlier stage during the preliminary tremor. In the major tremor stage, this out-of-plane displacement develops also in the side plates under the 3-directioned load. In this model, the horizontal displacement at the top of the column is not so significant.

Under the after shock, out-of-plane deformation develops during the preliminary tremor under either the 1-directioned load and the 3-directioned load, and up to final stage, these two types of load bring almost same deformation patterns as shown in the figure 8 .

\section{Figure 6. Displacement Pattern under Seismic Load \\ Figure 7. Displacement Pattern under Seismic Load \\ Figure 8. Displacement Pattern under Seismic Load}

\subsection{Displacement hysteresis response}

\subsubsection{Displacement caused by the main shock}

In Figure 9, displacement for E-W direction at the top of the column caused by the main shock is plotted. In this figure, the thick line shows the displacement under the 3directioned seismic load, middle line under the 2-directioned load for N-S and E-W, and the thin line denotes the displacement under the load of only E-W component.

When the column is not stiffened, very large displacement is developed except the 1directioned load for the concrete-filled column. In the earlier stage before the time reached to 4 seconds, although it is not clear in the figure due to the scale for the large displacement, the model NSNC is subjected to the displacement of -163 to $+107 \mathrm{~mm}$ under the 3-directioned load and -28 to $+128 \mathrm{~mm}$ under the 1-directioned load. The model NSWC with the filled-in concrete, the column sways within $\pm 50 \mathrm{~mm}$ up to 4 seconds. After the time of 4 seconds, displacement of these two models increases almost gradually without significant shaking, and the column is reached to the ultimate state. At the final stage, the model NSWC, which is concrete-filled and not stiffened column, has the displacement $\delta$ of $\delta=2962 \mathrm{~mm}$ at $t=9.21 \mathrm{sec}$. under the 3-directioned load, and under the 2-directioned load of N-S and E-W components, the displacement reached to $\delta=2535 \mathrm{~mm}$ at $t=8.12 \mathrm{sec}$. On these two cases, the column snapped just above the concrete and almost fell down at the final stage as shown in the section 4.2 of this paper. However, under 1-directioned load, $\delta=316 \mathrm{~mm}$ at $t=9.61 \mathrm{sec}$. and $\delta=299 \mathrm{~mm}$ at $t=10.00 \mathrm{sec}$. Thus, in this model, the multi-directioned seismic load has much severe influence to the column behaviour.

On the model NSNC with no stiffener and without concrete, the large displacement develops in the every load cases, and it exceeds $4000 \mathrm{~mm}$ at $t=7.78 \mathrm{sec}$. under the 3 directioned load. On this model, even 1-directioned load brings the displacement of $3569 \mathrm{~mm}$ at $t=8.29 \mathrm{sec}$.

Figure 9 Displacement at the top of the column (Main Shock) 
When the column has stiffeners, the column sways around $\delta=0$ up to the time is reached to about $t=4$ seconds. At $t=3.86 \mathrm{sec}$., the column is struck by the large shock of 1675 gals, and the median displacement of the column shaking is shifted to $\delta=100$ to $200 \mathrm{~mm}$ on the case that the column has no filled-in concrete. That is, under the 3-directioned load, the column sways around $160-200 \mathrm{~mm}$ and under the mono-direction load, it is around $100 \mathrm{~mm}$ after the major tremor attacked. When the column is filled with concrete, after the shock at $t=3.86 \mathrm{sec}$, the median of the column shaking shifted to approx. $20 \mathrm{~mm}$ under the 3directioned load although the median remains $0 \mathrm{~mm}$ with the 1-directioned load. The shaking period of these models is about $0.4 \mathrm{~Hz}$ for the column without the concrete and about $0.3 \mathrm{~Hz}$ for the column with filled-in concrete, which are close to the natural period of the columns.

Thus, this figure indicates that the 3-directioned seismic load of the main shock brings generally larger displacement than the 1-directioned load. However, the displacement is much smaller than one of the non-stiffened columns.

\subsubsection{Displacement caused by the after shock}

Figure 10 shows the displacement hysteresis of the columns under the after shock. By the after shock, all 4 models sway within $\delta= \pm 50 \mathrm{~mm}$ in the earlier stage within the preliminary tremor, and after the time is about $5 \mathrm{sec}$, the median displacement of shaking is shifted. Unlike to the main shock, fatal collapse is not observed in all models. This is due to the fact that the tremor of the after shock contains mainly the higher frequency waves.

The significant difference of behaviour caused by the after shock is that the 1directioned seismic load gives the larger displacement than the 2-directioned or 3-directioned load, in particular in the models with no stiffener. At the final stage, the column with no concrete is sways around about $\delta=0 \mathrm{~mm}$ under the 2- or 3-directioned load, although it is about $-150 \mathrm{~mm}$ by the 1-directioned load on the model with no concrete. On the concretefilled columns, it sways around $-60 \mathrm{~mm}$ under the 2- or 3-directioned load, and $-120 \mathrm{~mm}$ under the 1-directioned load. In the after shock, at $t=4.79 \mathrm{sec}$., large shock attacks for E-W direction and N-S direction almost simultaneously. Therefore, under the after shock with 3component of the seismic load, the column is subjected to the diagonally directed load. Thus, in the results, in this case, the column is subjected to the load for relatively stiff direction.

\section{Figure 10 Displacement at the top of the column (After Shock)}

\subsection{Maximum and residual Column-top displacement}

Tables 3 and 4 show the maximum and the residual horizontal displacement at the top of the columns. In this table, the horizontal displacement $\delta$ is calculated with the displacement for $x$ and $y$ directions, $\delta_{\mathrm{x}}, \delta_{\mathrm{y}}$, as $\delta=\sqrt{\delta_{x}{ }^{2}+\delta_{y}{ }^{2}}$, and the residual displacement is estimated as the average of the last two periods of the oscillation.

Under the main shock, when no stiffener is installed, all models collapse almost completely with the all 3 cases of the N-S, E-W and U-D loads except the case with filled-in concrete (mode NSWC) under the 1-directioned load. In these tables, "_" means that the columns collapse almost completely at their final stage, and no effective maximum or residual displacement can be obtained for such cases.

This table indicates that, under the main shock, the 2- or 3-directioned load generally 
brings larger displacement on the models in which the stiffeners are installed. The maximum displacement of the model WSNC is $285.1 \mathrm{~mm}$ under the 3-directioned load, and this value of the displacement is 1.8 times of the displacement by the 1-directioned load. On the residual displacement of this model, the 3-directioned load brings $230.5 \mathrm{~mm}$ and $247 \%$ of the 1directioned load. According to the Japanese design codes, the allowable residual displacement at the top of the column is $1 \%$ of the column depth. The current models have their depth of $10 \mathrm{~m}$, therefore, the allowable displacement is $10 \mathrm{~cm}$. However, the residual displacement of the model WSNC exceeds the allowable value under all three types of the seismic load. When the concrete is filled in the column, the displacement is much smaller than one of the model without concrete. That is, the model WSWC has the residual displacement of $20.5 \mathrm{~mm}$ under the 3 -directioned load that is only $8 \%$ of the model WSNC, although this is almost twice of the displacement under 1-directioned load.

Unlike to the main shock, the after shock brings the different trends of the displacement. The maximum displacement under 3-directioned load of the after shock is smaller than that of the 1-directioned load on the all models. For example, the model NSNC has the maximum displacement of $74.1 \mathrm{~mm}$ under the 3 -directioned load and this is $39 \%$ of one under the 1-directioned load.

On the residual displacement, the models with no concrete (models NSNC and WSNC) have the larger displacement under the 3-directioned load than one of under the 2directioned load, however, all models have the smaller displacement under the 3-directioned load than those under the 1-directioned load.

\section{REMARKS ON THE RESULTS}

As described in the section 4, under the main shock, the 3-directioned seismic load brings larger displacement than the 1-directioned load, and models NSNC and NSWC collapsed almost completely in their final stage. On the other hand, under the after shock, 3directioned load has small effect and all models do not collapse up to the final stage. According to the Table 1, models NSNC and NSWC have their natural period of 0.415 seconds and 0.316 seconds, and the models WSNS and WSWC, which are not collapsed, have 0.349 seconds and 0.310 seconds. This fact means that the natural period may not be a cause of the collapse.

In this section, remarks are given with the loci of the top of the columns.

\section{Figure 11 Loci of the top of the column (Main Shock) Figure 12 Loci of the top of the column (After Shock)}

Figures 11 and 12 show loci of the displacement at the top of the columns under the 3-directioned load. Within these figures, figure 11 is the loci of the main shock and figure 12 of the after shock. The horizontal axes ( $x$-axes) of these figures are the displacement for the East-West direction and the $y$-axes refer for the North-South direction. As mentioned above, the models NSNC and NSWC collapsed almost completely at their final stages under the main shock, and they have very large displacement for E-W direction. Therefore, it should be noted that the scale for the $x$-axes of these two models in the figure $\mathbf{1 1}$ is different of other models. For these two models, loci plotted with the same scale to other models are provided for only the earlier stage in the figure 11. 
Figures 11 and 12 indicate that all models except the model NSWC have the deformation of about $\pm 50 \mathrm{~mm}$ not only for $x$-direction but also for $y$-direction in the earlier stage. In particular, the model NSNC has the larger displacement for $x$-direction of $-150 \mathrm{~mm}$ to $+100 \mathrm{~mm}$ in the initial stage. This fact and the fact shown in the figure 9 suggest that, in the model NSNC, the displacement of the initial stage give a severe damage to the column, and the damage causes the total collapse of the column. On the other hand, the column NSWC is subjected relatively smaller displacement in the earlier stage. However, after the time is reached to 4 seconds, the column shifts for $x$ direction of $500 \mathrm{~mm}$, then total collapse is initiated.

The model WSNC in which stiffeners are installed deforms around the original location in the earlier stage with $\pm 50 \mathrm{~mm}$ for either $x$ and $y$ directions, then the displacement shifts to $\mathrm{x}$ direction of $200 \mathrm{~mm}$. As described in the section 4.4, the residual displacement of this model is about $230 \mathrm{~mm}$. Thus, this model sways around its original location in the earlier stage, then around the residual displacement.

On these 3 models, the large deformation begins developing after about 4 seconds. In the main shock, the large shock of the major tremor arises at about 3.8 seconds from the beginning of the preliminary tremor and the maximum acceleration is 1675 gals is observed at 3.86 seconds from the beginning, as described in the section 3. Although the detail is not shown in the section 3, this largest acceleration is oriented for the positive direction of the EW component. Thus, these 3 models collapse due to the large shock caused by the major tremor. In contrast with these three models, the model WSWC (the column with stiffeners and with the filled-in concrete) sways around the original location even after the major tremor begins. The section stiffness of the column of this model is of course same to the model WSNC. Therefore, the filled-in concrete is considered to influence the dynamic behaviour of the column.

In the after shock, the maximum acceleration of 2036 gals are observed at 4.79 seconds as shown in the section 3. By the after shock, the center of the swaying of the models except NSNC shift -30 or $-50 \mathrm{~mm}$ (for the negative direction of the EW component) after 5 seconds of the beginning under the 3-directioned seismic load. However, the largest acceleration of the after shock is oriented for the Southeast direction, and not for the East. This largest acceleration over 2000 gals in the after shock arises very momentarily (approximately 0.01 seconds) for the Southeast direction. On the other hand, the ground acceleration of 800 to 1300 gals arises at the time of 4.74 seconds for 0.04 seconds, and at the time of 5.00 seconds for 0.07 seconds, for the West direction ( $-x$ direction). Therefore, in the after shock, such acceleration for $-x$ direction has the larger effect to the column behaviour.

However, by the after shock, all models have smaller displacement than one by the main shock. In addition, on the model NSNC, 1-directioned seismic load brings the larger displacement than the 3-directoined load. As it has been described, in the after shock, the larger ground motion has not only the EW component but also the NS component. This means that, in the after shock, the seismic load acts the diagonal direction of the column section, i.e. relatively stiff direction. Thus, these are the reason that the after shock brings smaller displacement than the main shock even if the after shock has the larger ground acceleration, and that the 1-directioned load brings then larger displacement in certain case.

This fact indicates that, in the seismic design, at least few earthquake records are required for the analysis, and that both 1-directioned load and the 2- or 3-directioned load must be considered. 


\section{CONCLUSION}

In this paper, dynamic behaviour of steel box columns under the seismic load is studied. The dynamic analyses are made under the seismic load with one component (seismic load for only East-West component), two components (East-West and North-Souse components) and all three components (East-West, North-South and Up-Down), and the results are discussed on the effect of the seismic load having two or three components.

In the Japanese current code for the seismic design of bridges, seismic load for only one direction is considered, because it is assumed to be very rare that an earthquake has the large shock for two or three directions simultaneously. However, the results shown in this paper indicates that 2- or 3-directioned seismic load may cause much severer damage to the columns. On the other hand, according to the characteristics of the earthquake, onedirectioned seismic load brings larger influences to the column behaviour. Thus, in the seismic design of a bridge pier, the safety check should be made for both the one-directioned load and 2- or 3- directioned load.

\section{REFERENCES}

[1] Shimizu,S., Kameko,M. \& Yamamoto,T., Post-Stiffening of Partially Concrete-Filled Steel Box Columns, Proc. of Stability of Structures I $X^{\text {th }}$ Symposium, Zakopane, Poland, 2000, pp255-262.

[2] Shimizu,S. \& Iwamoto,N, Behavior of a concrete filled steel box column with considering delamination of steel-concrete interface. Proc. of Stability of Structures $X^{\text {th }}$ Symposium, Zakopane, Poland, 2003, pp379-384.

[3] Shimizu,S., A Dynamic Analysis of a Partially Concrete-filled Steel Column with Considering Delamination of the Steel-Concrete Interface, Proc. of the 8th Conference on Shell structures theory and applications (SSTA2005), Gdansk-Jurata, Poland, 2005, pp615618.

[4] Shimizu, S. \& Watanabe, T., Behaviour of concrete-filled steel columns under the seismic loading, Thin Walled Structures, No.10-11, Vol.45, 2007, pp921-926

[5] Shimizu, S. \& Watanabe, T., Behaviour of concrete filled steel columns under the seismic loading, Proc. of Stability of Structures XI ${ }^{\text {th }}$, Zakopane, Poland, 2006, pp359-366

[6] Watanabe, T. \& Shimizu, S., An Earthquake Response Analysis of Partially Concretefilled Steel Column with Considering Debond, Steel Construction Engineering, JSSC(Japanese Society of Steel Construction), Vol.14, 2006, 49-58.(in Japanese) 


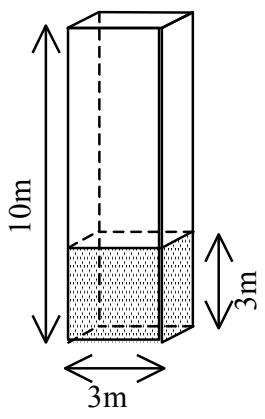

(a) Column Outline

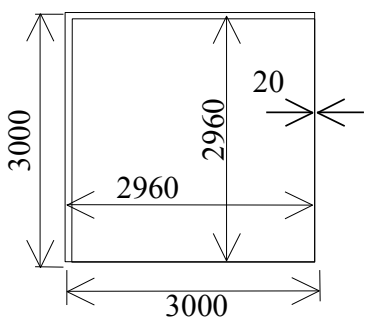

(b) Column Section without Stiffener

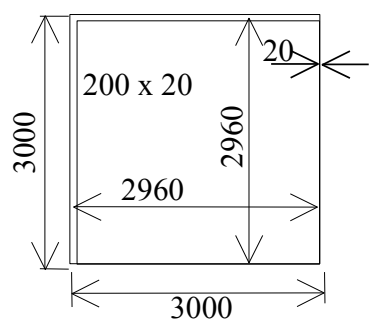

(c) Column Section with Stiffeners

Figure 1 Typical Numerical 


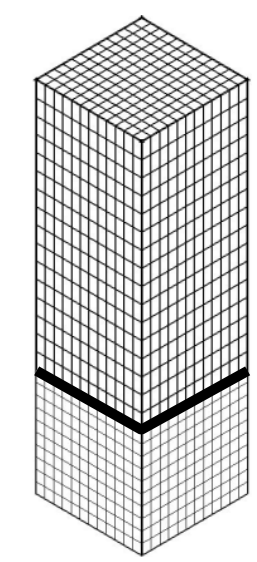

Figure 2 FEM Mesh Pattern 


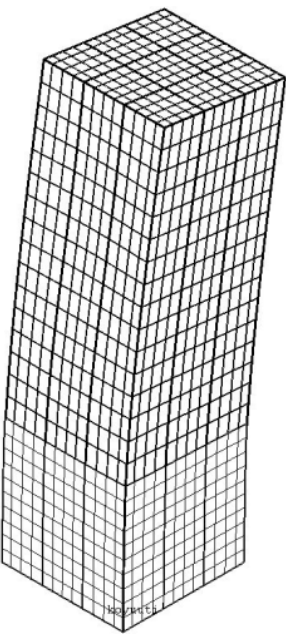

(a) 1-st mode

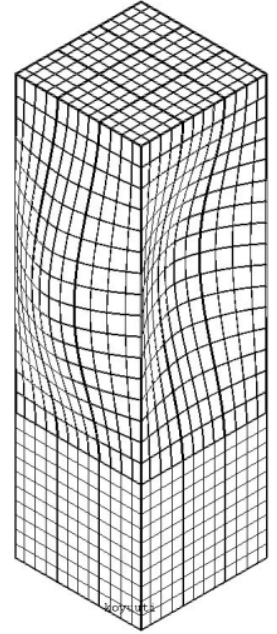

(b) 2-nd mode

Fig.3 Examples of Natural mode of columns with stiffeners and filled with concrete 

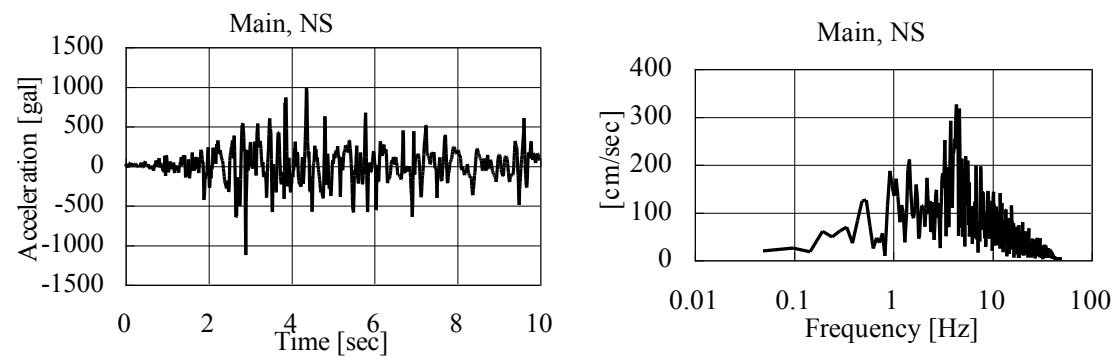

(a) Ground acceleration (left) and Fourier spectrum (right) of N-S component
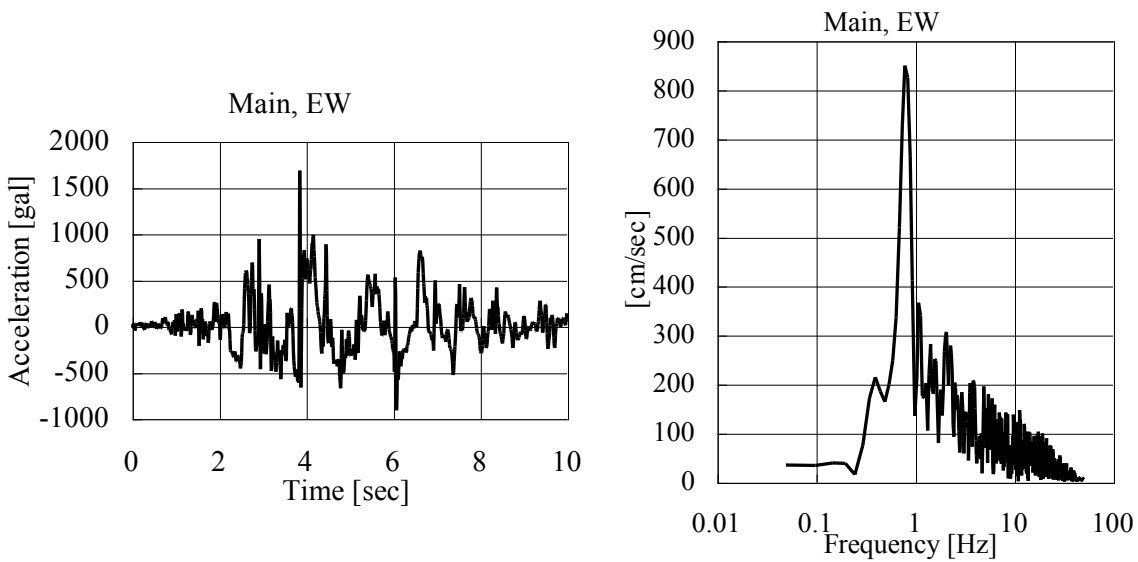

(b) Ground acceleration (left) and Fourier spectrum (right) of E-W component
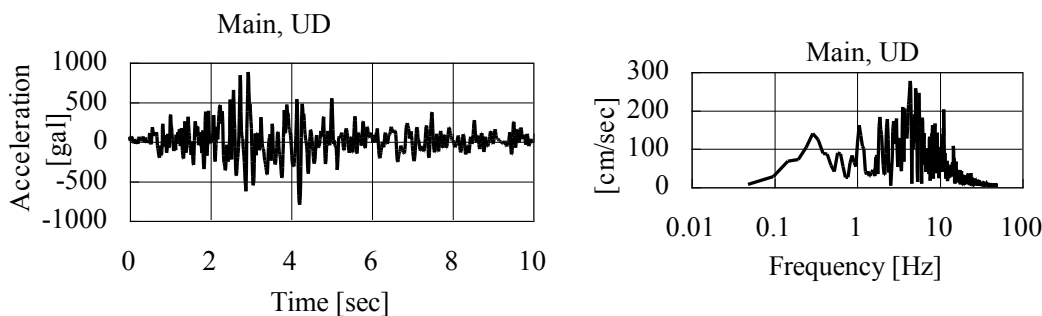

(c) Ground acceleration (left) and Fourier spectrum (right) of U-D component

Figure 4 Seismic Load of Main Shock 

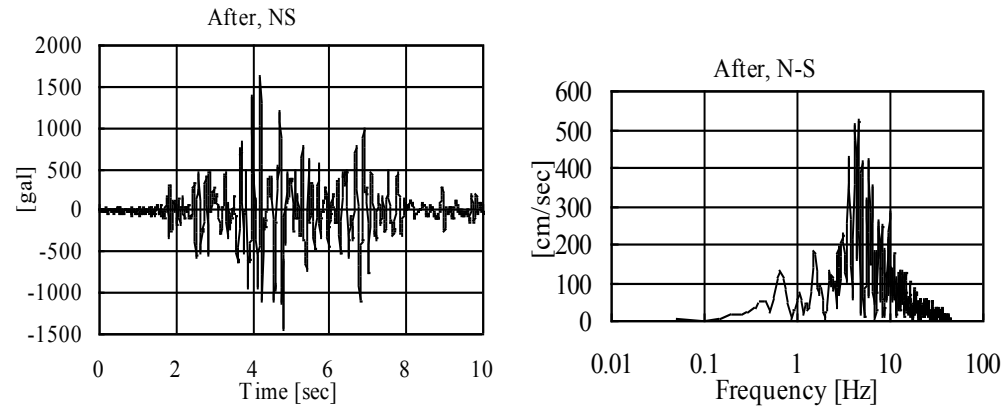

(a) Ground acceleration (left) and Fourier spectrum (right) of N-S component

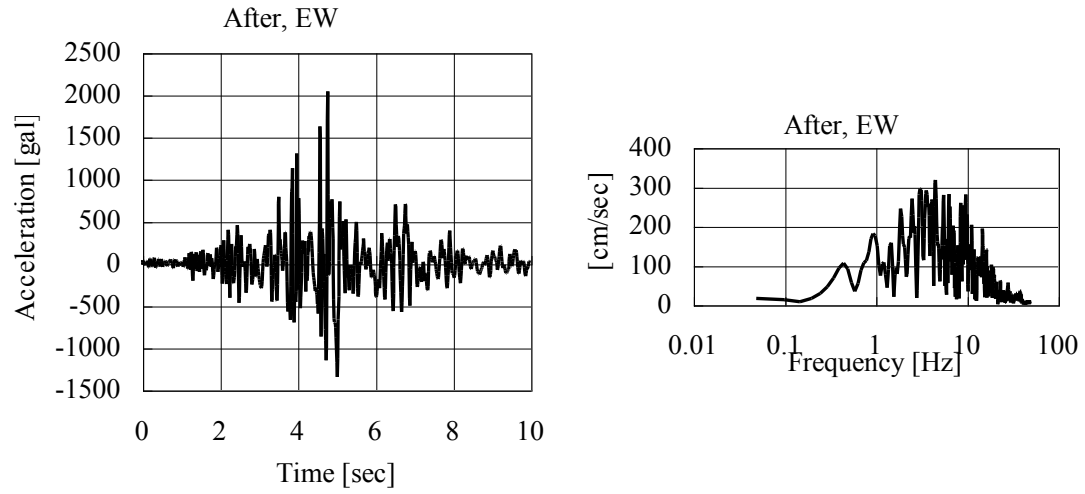

(b) Ground acceleration (left) and Fourier spectrum (right) of E-W component
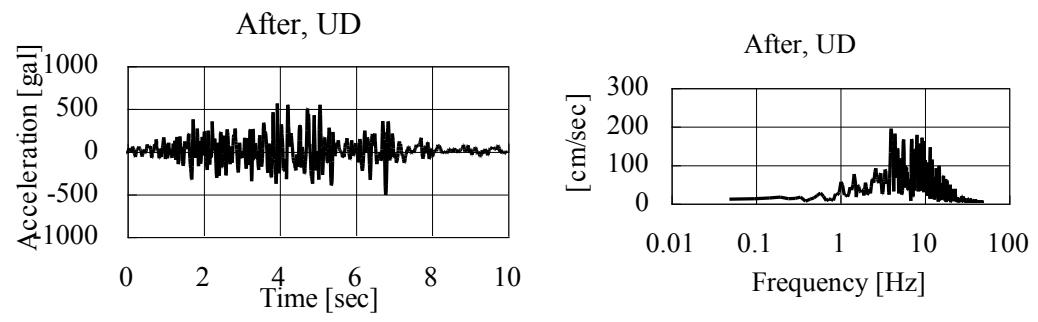

(c) Ground acceleration (left) and Fourier spectrum (right) of U-D component

Figure 5 Seismic Load of Maximum After Shock 


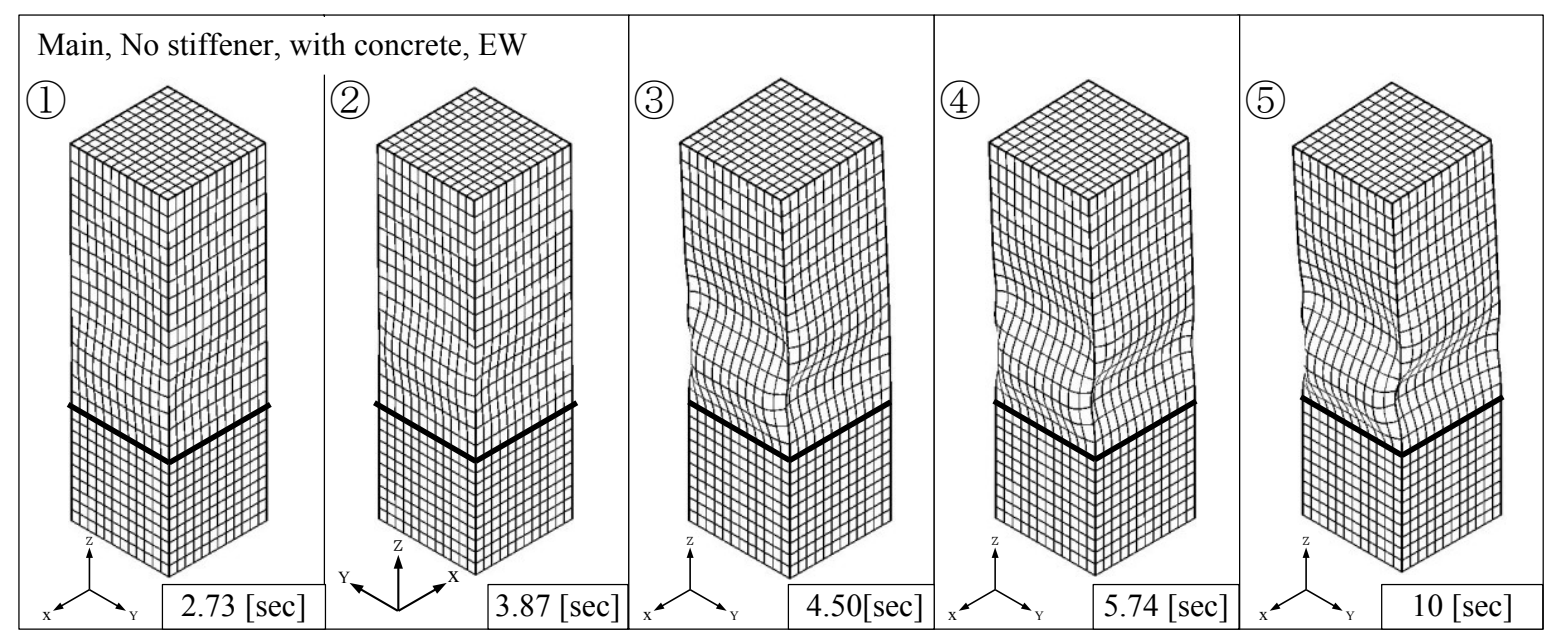

(a) Under 1-direction (E-W) seismic load

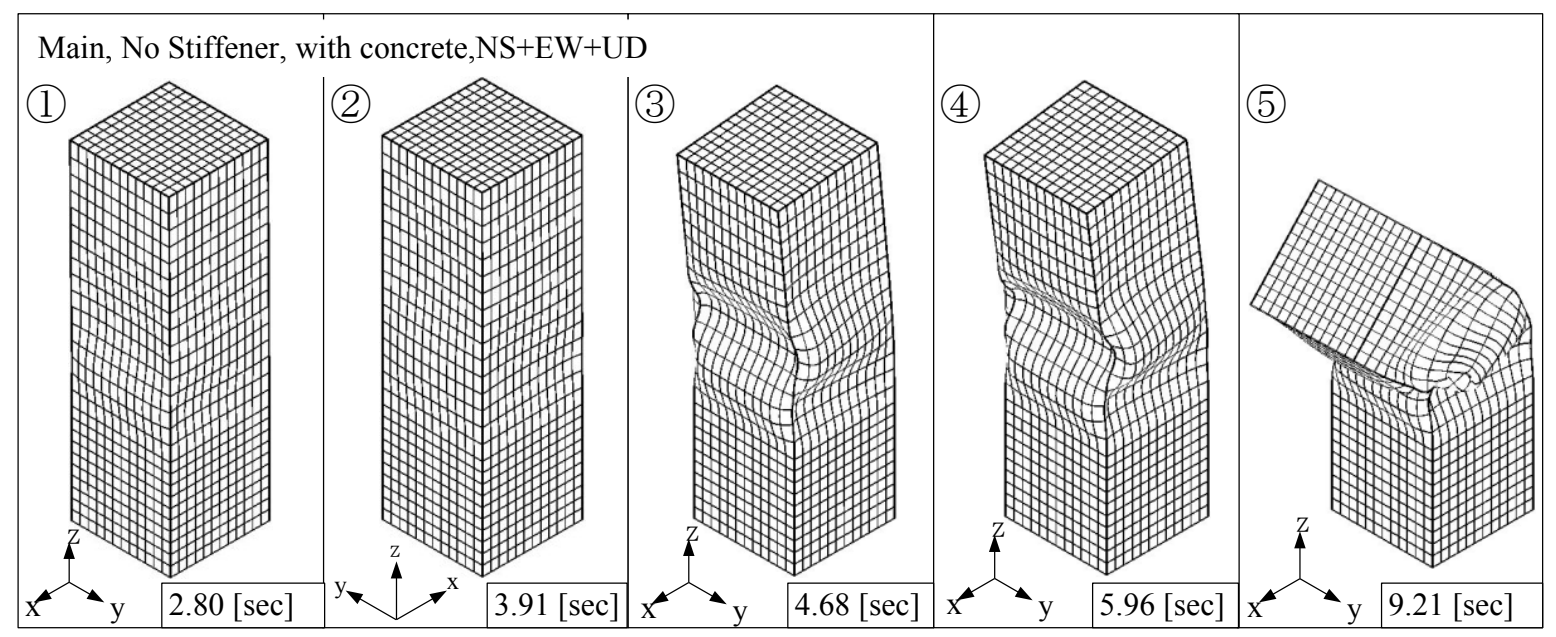

(b) Under 3-directioned seismic load

Figure 6. Displacement Pattern under Seismic Load

(Main Shock, Models with no stiffener, with concrete) 


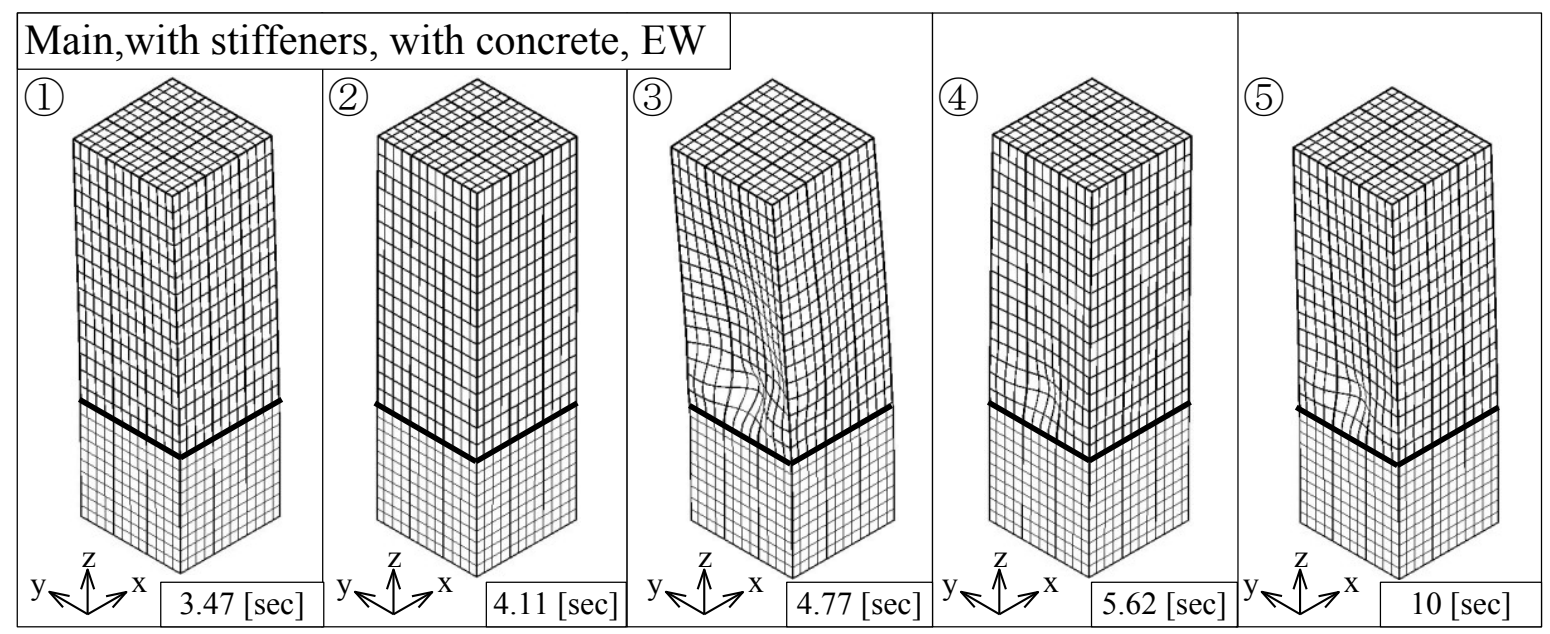

(a) Under 1-direction (E-W) seismic load

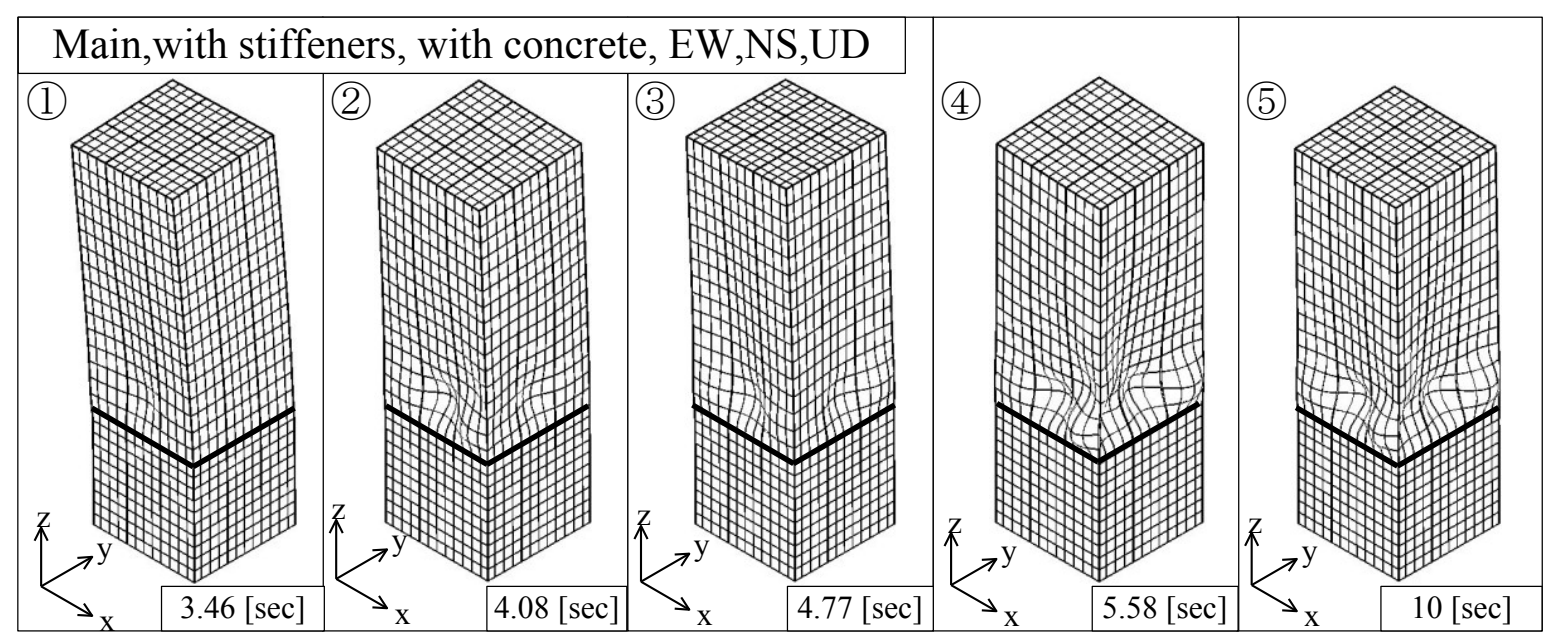

(b) Under 3-directioned seismic load

Figure 7. Displacement Pattern under Seismic Load

(Main Shock, Models with stiffener, with concrete) 


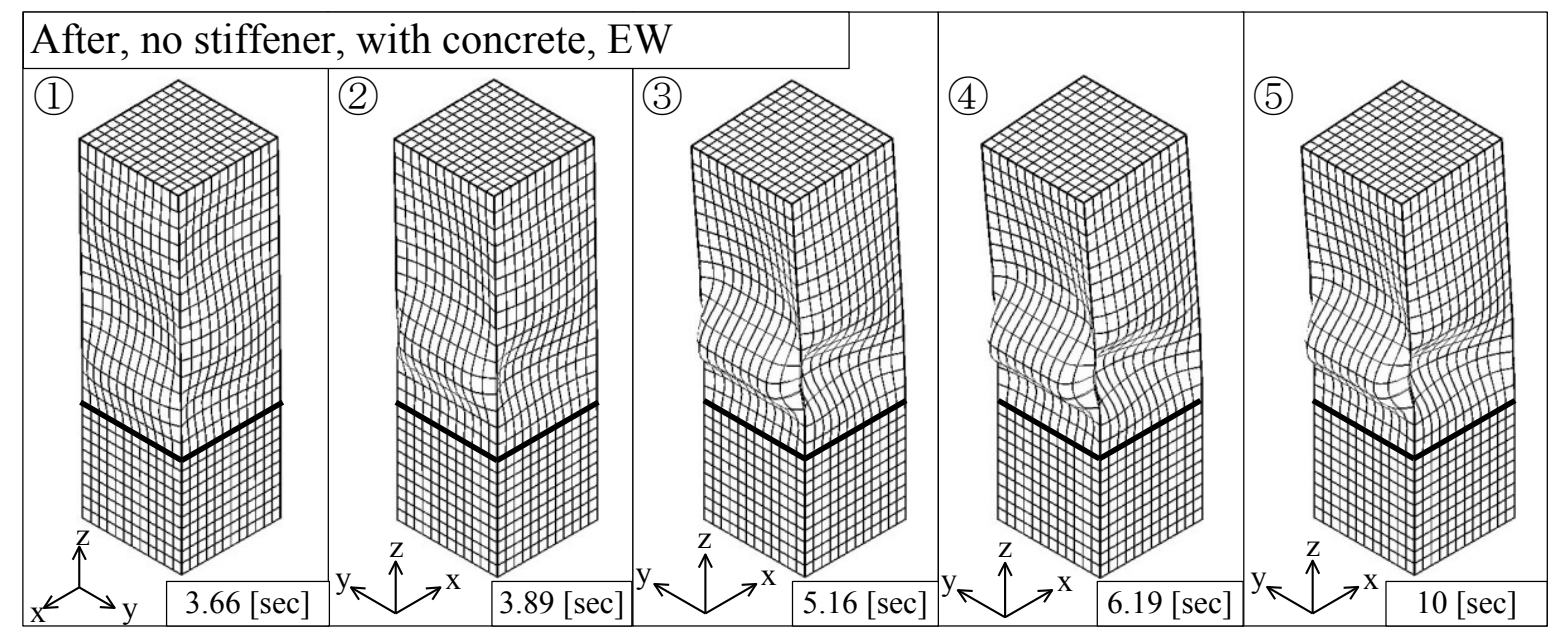

(a) Under 1-direction (E-W) seismic load

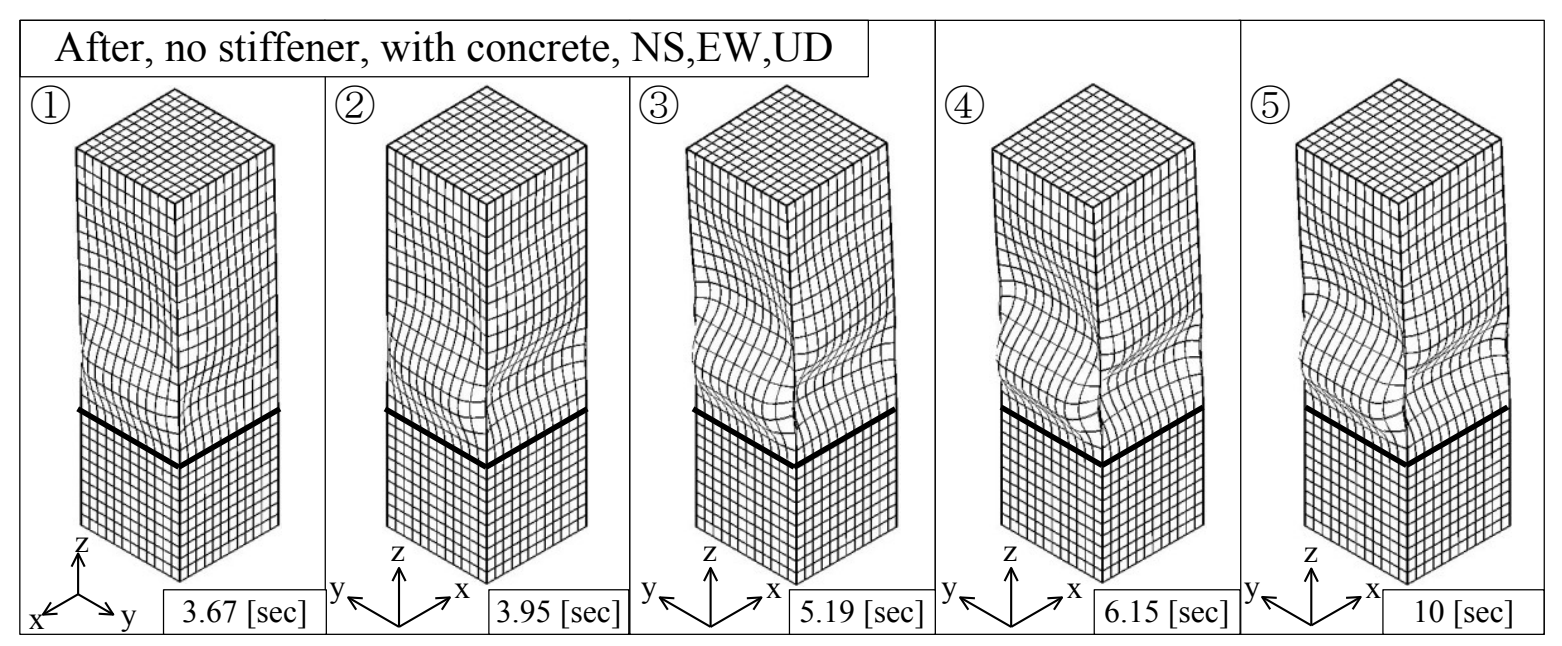

(b) Under 3-directioned seismic load

Figure 8. Displacement Pattern under Seismic Load (After Shock, Models with no stiffener, with concrete) 

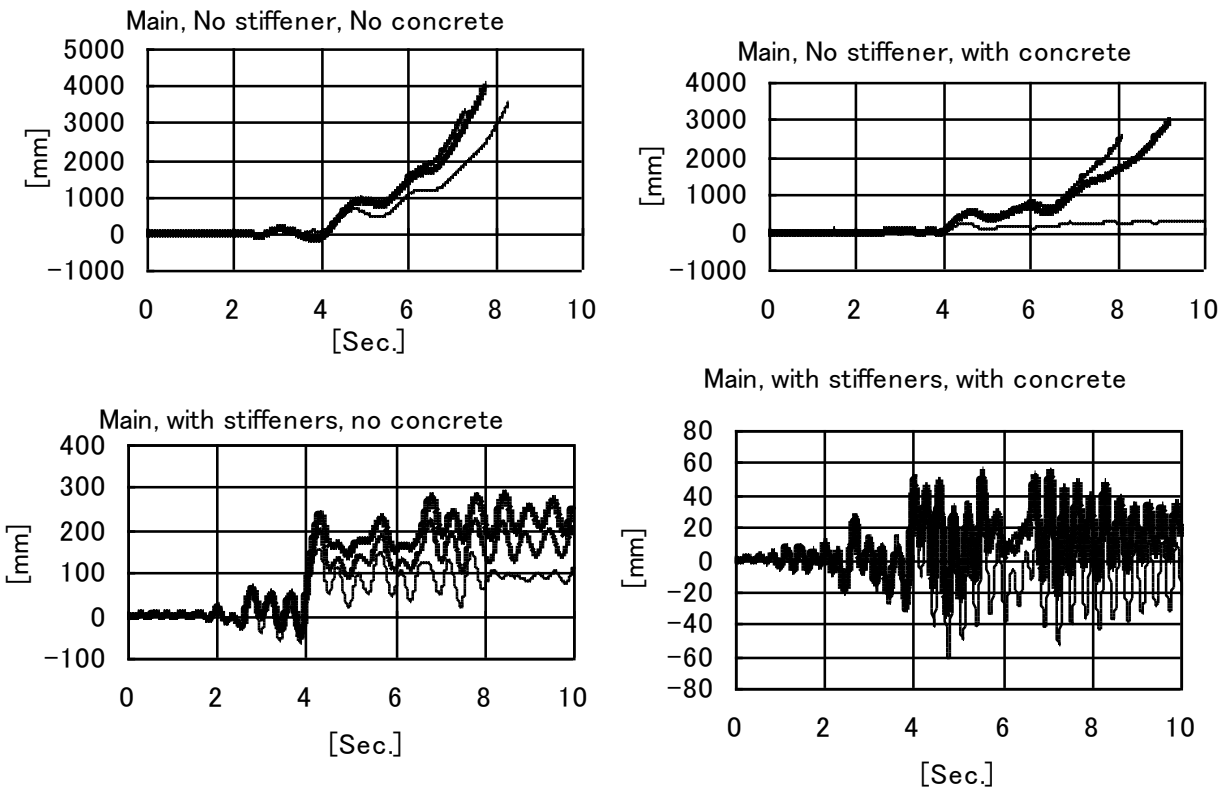

Figure 9 Displacement at the top of the column (Main Shock) 

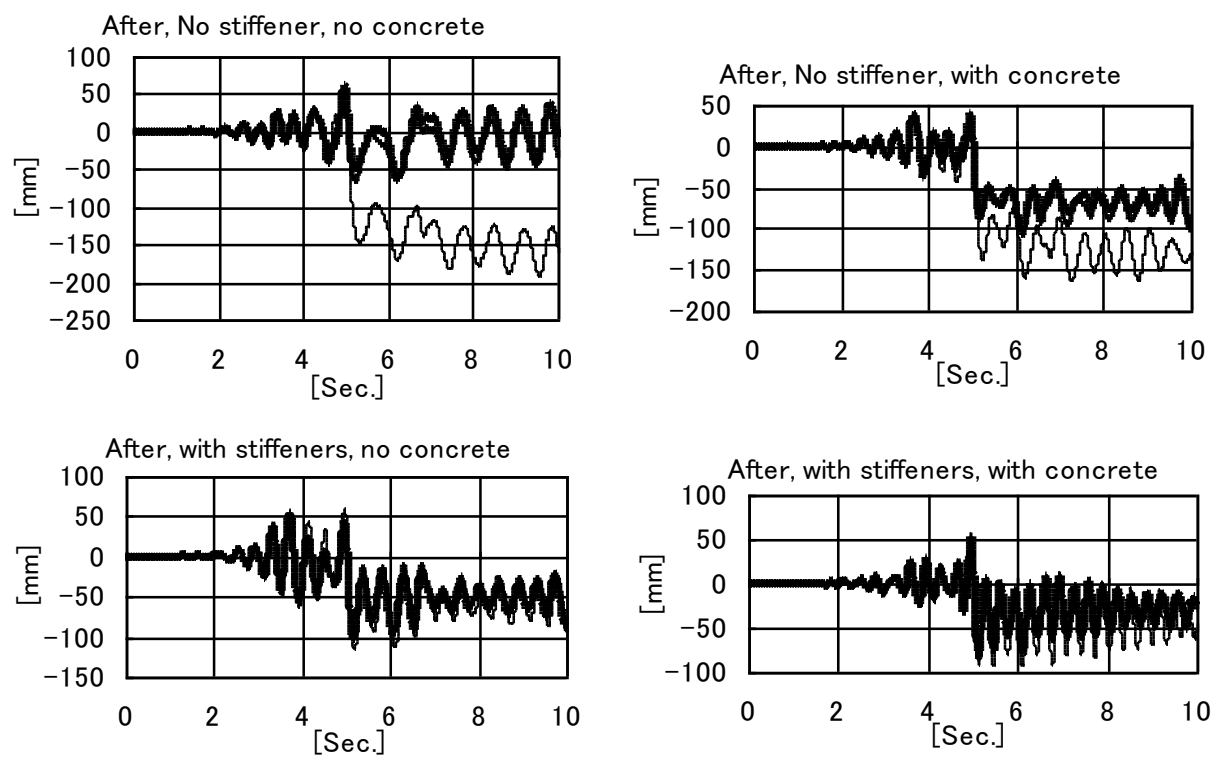

Figure 10 Displacement at the top of the column (After Shock) 

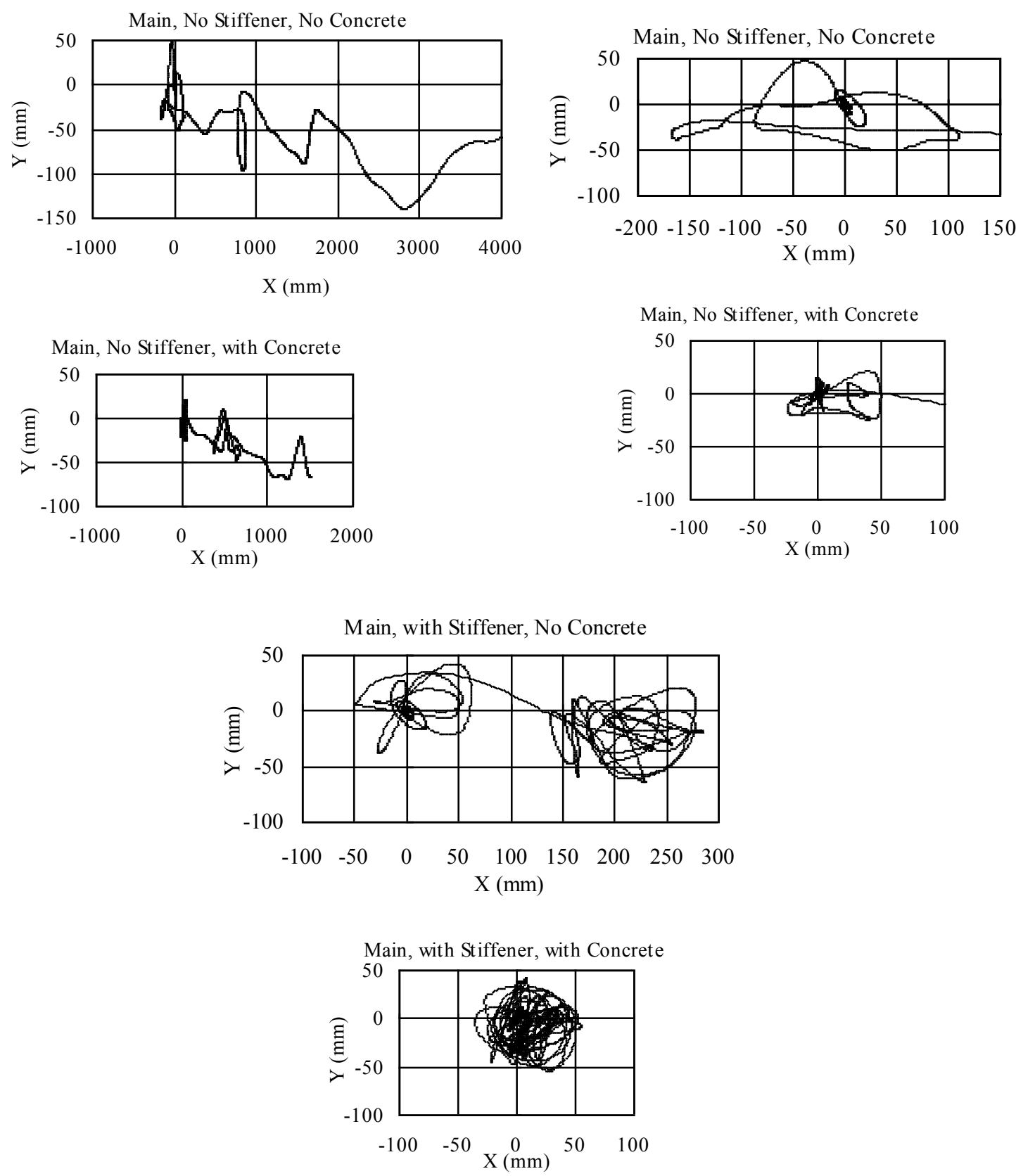

Figure 11 Loci of the top of Columns (Main Shock) 

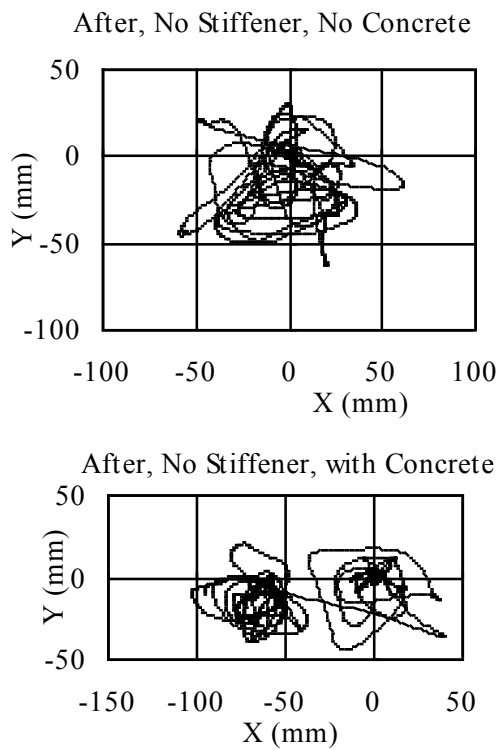

After,with Stiffener, No Concrete
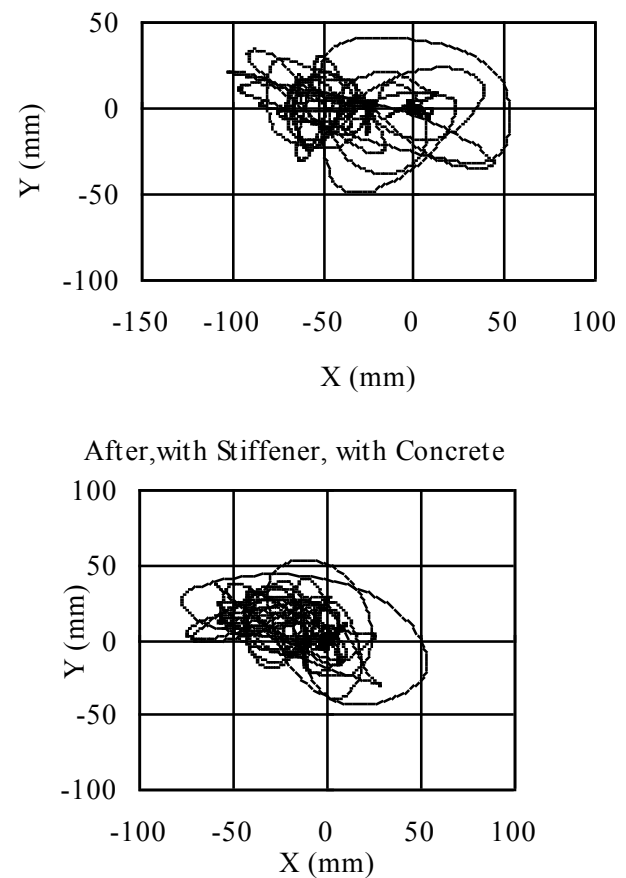

Figure 12 Loci of the top of Columns (After Shock) 
Table 1 Natural Period and Natural Frequency

\begin{tabular}{ccccc}
\hline & \multicolumn{2}{c}{ No Stiffener } & \multicolumn{2}{c}{ With Stiffeners } \\
\hline mode & No Concrete & With Concrete & No Concrete & With Concrete \\
\hline 1-st & $0.415(2.410)$ & $0.316(3.165)$ & $0.394(2.538)$ & $0.310(3.226)$ \\
\hline 2-nd & $0.165(6.061)$ & $0.145(6.897)$ & $0.101(9.901)$ & $0.089(11.24)$ \\
\hline \multicolumn{4}{c}{ Natural Period (Sec) and Natural Frequency $(\mathrm{Hz}$, in parentheses $)$}
\end{tabular}

Table 2 Factors $\alpha$ and $\beta$

\begin{tabular}{ccccc}
\hline & \multicolumn{2}{c}{ No Stiffener } & \multicolumn{2}{c}{ With Stiffeners } \\
\hline $\begin{array}{c}\text { coefficient } \\
\mathrm{s}\end{array}$ & No Concrete & With Concrete & No Concrete & $\begin{array}{c}\text { With } \\
\text { Concrete }\end{array}$ \\
\hline$\alpha$ & 0.434 & 0.545 & 0.507 & 0.631 \\
\hline$\beta$ & $7.516 \times 10^{-4}$ & $6.334 \times 10^{-4}$ & $5.126 \times 10^{-4}$ & $4.399 \times 10^{-4}$ \\
\hline
\end{tabular}

Table 3 Abbreviations for Numerical Models

\begin{tabular}{ccc}
\hline & no stiffener & with stiffeners \\
\hline no concrete & NCNS & NCWS \\
\hline concrete-filled & WCNS & WCWS \\
\hline
\end{tabular}


Table 4 Maximum Column-Top Displacement

\begin{tabular}{llllllll}
\hline \multicolumn{3}{c}{ Main Shock } & \multicolumn{5}{c}{ After Shock } \\
\hline Models & EW & NS+EW & NS+EW+UD & EW & NS+EW & NS+EW+UD \\
\hline \multirow{2}{*}{ no stiffener } & no concrete & - & - & - & $156.3 \mathrm{~mm}$ & $16.2 \mathrm{~mm}$ & $32.0 \mathrm{~mm}$ \\
\cline { 2 - 8 } & concrete-filled & $301.6 \mathrm{~mm}$ & - & - & $130.6 \mathrm{~mm}$ & $77.0 \mathrm{~mm}$ & $67.8 \mathrm{~mm}$ \\
\hline \multirow{2}{*}{ with stiffeners } & no concrete & $93.3 \mathrm{~mm}$ & $166.9 \mathrm{~mm}$ & $230.5 \mathrm{~mm}$ & $57.5 \mathrm{~mm}$ & $48.3 \mathrm{~mm}$ & $54.0 \mathrm{~mm}$ \\
\cline { 2 - 9 } & concrete-filled & $10.4 \mathrm{~mm}$ & $24.2 \mathrm{~mm}$ & $20.5 \mathrm{~mm}$ & $38.8 \mathrm{~mm}$ & $37.3 \mathrm{~mm}$ & $30.0 \mathrm{~mm}$ \\
\hline
\end{tabular}

Table 5 Residual Column-Top Displacement

\begin{tabular}{ccccccccc}
\hline & & \multicolumn{3}{c}{ Main Shock } & \multicolumn{3}{c}{ After Shock } \\
\hline \multirow{2}{*}{ Models } & EW & NS+EW & NS+EW+UD & EW & NS+EW & NS+EW+UD \\
\hline \multirow{2}{*}{ no stiffener } & no concrete & - & - & - & $190.0 \mathrm{~mm}$ & $76.5 \mathrm{~mm}$ & $74.1 \mathrm{~mm}$ \\
\cline { 2 - 10 } & concrete-filled & $262.3 \mathrm{~mm}$ & - & - & $162.0 \mathrm{~mm}$ & $108.2 \mathrm{~mm}$ & $103.5 \mathrm{~mm}$ \\
\hline \multirow{2}{*}{ with stiffeners } & no concrete & $158.0 \mathrm{~mm}$ & $222.0 \mathrm{~mm}$ & $285.1 \mathrm{~mm}$ & $115.3 \mathrm{~mm}$ & $107.7 \mathrm{~mm}$ & $105.0 \mathrm{~mm}$ \\
\cline { 2 - 10 } & concrete-filled & $60.8 \mathrm{~mm}$ & $67.3 \mathrm{~mm}$ & $61.4 \mathrm{~mm}$ & $92.4 \mathrm{~mm}$ & $89.4 \mathrm{~mm}$ & $82.5 \mathrm{~mm}$ \\
\hline
\end{tabular}

